\title{
Functional characterization of drought resistance in peach (Prunus petsica (L.) Batsch) cultivars damaged with Sharka disease
}

\author{
V.A. Brailko ${ }^{1 *}$ I.V. Mitrofanova ${ }^{1}$, N.V. Mesyats $^{1}$, O.V. Mitrofanova ${ }^{1}$, S.V. Chirkov ${ }^{1,2}$ \\ 1 Federal State Funded Institution of Science "The Labor Red Banner Order Nikita Botanical Gardens - National Scientific Center of the RAS", Yalta, Russia \\ ${ }^{2}$ Faculty of Biology, Lomonosov Moscow State University, Moscow, Russia
}

DOI 10.18699/ICG-PlantGen2019-30

(c) Autors, 2019

*e-mail: valentina.brailko@yandex.ru

\begin{abstract}
The article presents a comparative analysis of resistance to air and soil drought on the South Coast of the Crimea in healthy Prunus persica (L.) Batsch plants and ones infected with Plum pox virus. The degree of damage to tree crowns varied from $10 \%$ to $80 \%$. Structural differences in virus-free and infected plants were revealed: a decrease in leaf thickness and palisade index, the formation of large intercellular spaces in spongy tissue, necrotization in palisade chlorenchyma and a greater number of crystalline inclusions in the cell cytoplasm. Under optimal conditions, the cultivars with the water-holding capacity of leaf tissues changing at infection were determined. The summer drought caused a decrease in the total water content in the leaf tissues; the total water content in asymptomatic plants was $59-70 \%$; in those affected, it decreased to $55 \%$, while the water deficit increased to $31 \%$. Thus, PPV damages significantly reduced plant resistance to abiotic stress of the summer period in the cultivars 'Karnavalniy', 'Pushistiy Ranniy', 'Demerdzhinskiy'.

Key words: drought tolerance; Prunus persica L.; Sharka disease; virus resistance; peach.
\end{abstract}

\section{Introduction}

Peach is one of the economically most valuable fruits, the world production of which is more than 24 tons per year. A major with growing Prunus L. cultivars is that they are damaged by Sharka disease (Plum pox virus, PPV) (Mitrofanova et al., 2000; Garcia and Cambra, 2007; Chirkov and Prikhod'ko, 2015; Mitrofanova et al., 2017; Shevchenko et al., 2017). The infected plants were characterized by disturbed metabolic and growth processes that affected their fruiting (Mitrofanova et al., 2014; Brailko et al., 2015; Buntsevich et al., 2016). PPVinfected plants were more affected by adverse environmental conditions. The disease was a cause of yield losses of up to $85-100 \%$ due to fruit quality deterioration and their premature fall (Mitrofanova et al., 2014; Clente-Moreno et al., 2015).

The aim of our study was to identify structural and physiological changes in the peach leaf tissues under $P P V$ infection. To achieve the goal, histological and physiological analyses of the leaf blades from healthy and damaged peach trees in the open-field collection of the Nikita Botanical Gardens - National Scientific Center (NBG-NSC) were performed.

\section{Materials and methods}

Twelve peach cultivars were studied: 'Demerdzhinskiy', 'Krymskiy Shedevr', 'Lakomiy', 'Mechta', 'Podarok Neveste', 'Pushistiy Ranniy', 'Strelets', 'Karnavalniy' (NBGNSC breeding), 'Ambergold', 'Dixired', 'Tulip', 'Cardinal' (introduced cultivars). The particular value of these genotypes is in their early maturity (fruits of the cultivars 'Krymskiy Shedevr', 'Podarok Neveste' ripen in the second decade of July), their better transportability ('Cardinal'), high flavour qualities ('Demerdzhinskiy', 'Lakomiy') and frost resistance (characteristic of the cultivars 'Demerdzhinskiy' and 'Pushistiy Ranniy'). Anatomical studies were performed on temporary slides (Pausheva, 1990), which were analyzed using an AxioScope A.1 microscope (Zeiss, Germany) and AxioVisionRel 4.8.2. software. Micrographs were taken with an AxioCamERc5s digital camera.

Changes in the water regime were assessed by the following parameters: total water content, water deficiency, waterholding capacity of leaf tissues (Lishchuk, 1991).

Statistical analysis of the data was made with STATISTICA 6.0.

\section{Results and discussion}

Due to the monitoring of peach collection plots, cultivars and hybrid forms with Sharka disease (PPV) symptoms were identified. On the leaf blades of the damaged plants, patterns of narrow, blurred stripes were observed, more rarely lightyellow or yellow rings, which were clearly visible in the light. Among the symptoms, wrinkled leaves should also be noted. The degrees of tree crown damage were different: less than $10 \%$ leaf damage was observed in 'Podarok Neveste'; from 10 to $40 \%$, in 'Demerdzhinskiy', 'Strelets', 'Karnavalniy', 'Krymskiy Shedevr', 'Dixired', 'Ambergold', 'Tulip', and 'Cardinal'; and from 40 to $80 \%$ of leaves were infected in 'Lakomiy', 'Pushistiy Ranniy', and 'Mechta'. During fruit ripening, color necrotic spots appeared on the leaves.

The leaf blades of these cultivars have a complex of common anatomical and morphological characteristics which are typical of the peach culture in general (Sokolova, Schoferistov, 1991). The leaves are bifacial, hypostomatic, their thickness is from 145 to $192 \mu \mathrm{m}$ (Figure 1, b), covered with a thick cuticle on both adaxial and abaxial surfaces (cuticle thickness from 6 to $18 \mu \mathrm{m}$ ). The mesophyll is dense, consisting of 5-8 layers, sometimes isopalisade. The leaf petiole on the cross section has a rounded-triangular shape; the vascular bundle is collateral closed, has the shape of a regular arc (Figure 1,a). The 


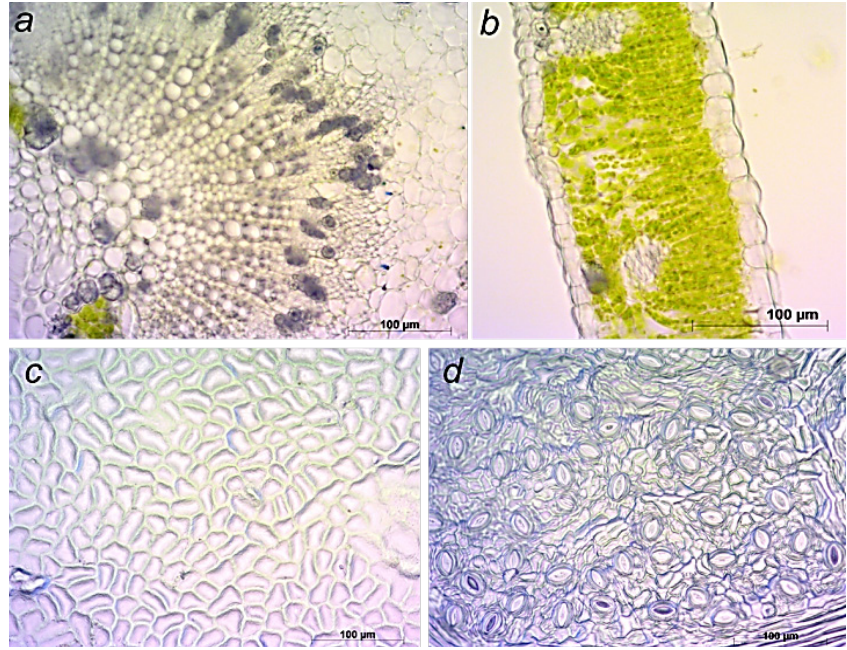

Figure 1. Leaf blade structure of asymptomatic $P$. persica trees, cultivar 'Pushistiy Ranniy': midvein (a), cross-section (b), casts of adaxial (c) and abaxial epidermis $(d)$.

epidermis is one cell layer thick; cell thickness is $31-48 \mu \mathrm{m}$ on the adaxial side and $12-16 \mu \mathrm{m}$ on the abaxial side. In terms of form, they are 5-7 angular, large on the adaxial leaf surface and small, elongated on the abaxial one (Figure 1, $c, d$ ). The stomatal apparatus of the anomocytic type, their number varies from 73 to 192 stomata $/ \mathrm{mm}^{2}$. The length of the stomatal pore is $25-32 \mu \mathrm{m}$.

The leaf blades of the damaged trees had a number of structural differences, compared with asymptomatic ones (see Figure 2, $a, b$ ), such as: a decrease in leaf thickness (by 8-12\%, noted in 'Lakomiy' and 'Krymskiy Shedevr'); a decrease in palisade index (in 'Lakomiy'), large intercellular spaces appeared in the spongy tissue; in most of the damaged leaves, no matter what cultivar, chloroplasts destruction began in the mesophyll layers adjacent to cover tissues and further through the mesophyll; necrosis began in palisade chlorenchyma; in the cell cytoplasm, a number of crystalline inclusions (calcium oxalate druses) significantly increased; the number of stomata in PPV-infected leaves significantly increased (1.2-2-fold) in 'Tulip' and 'Podarok Neveste'. Many authors who have studied the anatomical structure of leaves in various fruit crops note that drought-resistant plants are characterized by an isolateral small cell structure with tightly closed mesophyll cells (Sokolova, Shoferistov, 1991; Golubkova, 2014) Thus, the structural changes revealed can reduce the xerophytic properties of peach leaves in damaged cultivars.

Some authors (Elmanova, Opanasenko, 2010; Smykov et al., 2013; Drahavtseva et al., 2014) noticed a high drought tolerance of peach trees. In order to determine its degree, we assessed the water regime during the conditionally optimal and extreme vegetation periods of 2017 and 2018 (the weather conditions in summer 2017 did not have significant differences from the average long-term meteorological data, while in 2018 there were two peaks of hydrothermal stress: the maximum air temperature was $34{ }^{\circ} \mathrm{C}$, relative humidity decreased to $23 \%$, the non-rainfall period before sampling lasted from 21 to 26 days during the extreme period). In optimal moisture condi-

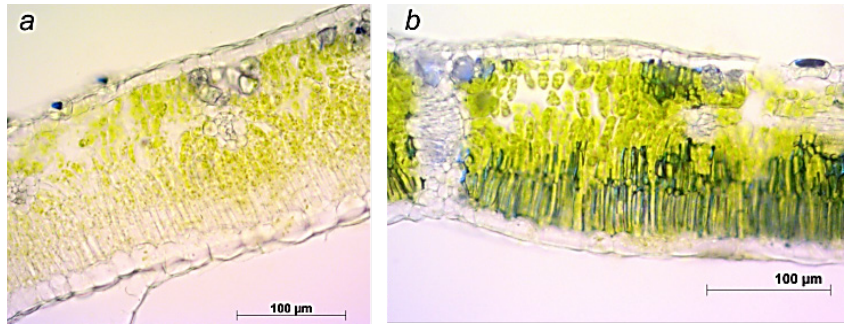

Figure 2. Leaf blade structure in PPV-infected $P$. persica trees, cultivars 'Lakomiy' (a) and 'Krymskiy Shedevr' (b). Original.

tions, the leaves were characterized with high water content (69-76\%). It should be noted that the value of the total water content in the leaves in May-June correlated with the amount of precipitation $(\mathrm{r}=0.41 \ldots 0.52)$. Water deficit at that time ranged from $4 \%$ ('Podarok Neveste', 'Krymskiy Shedevr', 'Ambergold') to $15 \%$ (damaged leaves in 'Karnavalniy', 'Mechta'). With the presented cultivar difference, in the optimal conditions of the growing season beginning, cultivars demonstrated changes in water regime when infection were revealed: 'Mechta', 'Pushistiy Ranniy', 'Cardinal'. Their water holding capacity decreased by $18-30 \%$ compared to asymptomatic leaves. Summer drought resulted in a decrease in the total water content in the leaf tissues; in asymptomatic plants, the water content was 59-70\%; in those affected, it decreased to $55 \%$ ('Karnavalniy', 'Pushistiy Ranniy', 'Ambergold'). A direct correlation of water content with relative air humidity $(\mathrm{r}=0.59 \ldots 0.83)$ was noted. Water deficit was $12-26 \%$ in healthy plants and $20-31 \%$ in affected ones (the maximum was in 'Karnavalniy', 'Ambergold' and 'Cardinal'). The correlation of water deficiency with average daily air temperature $(\mathrm{r}=0.59 \ldots 0.78)$ and relative air humidity $(\mathrm{r}=-0.47 \ldots-0.71)$ was revealed. In the infected plants of the cultivars 'Mechta', 'Karnavalniy', 'Ambergold' and 'Cardinal' sublethal water deficit was reached.

\section{Conclusions}

Thus, our research demonstrated that high drought tolerance is generally characteristic of the cultivars 'Krymskiy Shedevr', 'Dixired', 'Tulip' and 'Podarok Neveste'. PPV damage resulted in structural and functional changes that reduce resistance to abiotic stress (drought) in the cultivars 'Karnavalniy', 'Pushistiy Ranniy' and 'Demerdzhinskiy'.

\section{References}

Brailko V.A, Grebennikova O.A., Mitrofanova I.V., Mitrofanova O.V. Structural, functional and biochemical features in Canna $\times$ hybrida hort. plants with viral diseases. Subtropical and decorative gardening. 2015;55:139-145.

Buntsevich L.L., Kpstyuk M.A., Nenko N.I. Physiological and biochemical characteristics of the leaves of plum and decrease in the quality of its fruits during infection pox (PPV). Technologies of food and processing industries AIC-healthy food. 2016;5:38-42.

Chirkov S.N., Prikhod'ko Yu.N. Genetic diversity and population structure of Plum pox virus in Russia (review). Agricultural Biology. 2015;50(5):529-539.DOI 10.15389/agrobiology.2015.5.529eng 
Clemente-Moreno M.J., Hernandez J.A., Diaz-Vivancos P. Sharka: how do plants respond to Plum poxvirus infection? J. Exp. Bot. 2015;66: 25-35. https://doi.org/10.1093/jxb/eru428

Dragavtseva I.A., Savin I.Yu., Domozhirova V.V., Morenets A.S., Akhmatova Z.P., Zagirov N.G. Adaptation of the peach crop to the conditions of cultivation in the south of Russia. Horticulture and viticulture. 2014;6:35-40.

Elmanova T.S., Opanasenko N.E. Ecological and physiological features of peach. Kiev: Agrarian science, 2010. 152 pp.

Garcia J.A., Cambra M. Plum Pox Virus and Sharka Disease. Plant Viruses. 2007;1:69-79.

Golubkova I.M. Micromorphological structure of the leaf blades in the representatives of the genus Persica Mill. in the M.M. Gryshko National Botanical Garden. Bulletin of Biology and Medicine Problems. 2016;1(127):38-41.

Lischuk A.I. Method for determining the water-holding capacity for dehydration in the leaves of fruit crops. Physiological and biophysical methods in the selection of fruit crops: guidelines. Moscow: GNBS, $1991.68 \mathrm{pp}$.

Mitrofanova I.V., Mitrofanova O.V., Chirkov S.N., Lesnikova-Sedoshenko N.P. Methodological approaches to Sharka (Plum pox vi$r u s)$ detection and identification on the different species of genus Prunus. Works of the State Nikitsky Botanical Gardens. 2014;138: 137-161.

Mitrofanova I.V., Mitrofanova O.V., Lesnikova-Sedoshenko N.P., Ivanov P.A., Sheveleva A.A., Chirkov S.N. Three highly divergent groups of Plum pox virus strain D isolates coexist in stone-fruit plantings of Nikita Botanical Gardens, Crimea. Acta Hortic. 2017; 1163:117-122. https://doi.org/10.17660/ActaHortic.2017.1163.17.

Mitrofanova O.V., Slavgorodskaya-Kurpieva L.E., Mitrofanova I.V., Lukicheva L.A. Diagnostics of viral diseases and biotechnological ways of virus-free planting material of stone fruits obtaining. Yalta: Krympress, 2000. 45 pp.

Pausheva Z.P. Practicum in plant cytology. Moscow: Kolos. 1990. 283 pp.

Shevchenko S., Gorina V., Mitrofanova I. The influence of viral status on pollen Characteristics of some apricot cultivars. Agriculture \& Forestry. 2017;63(1):87-93. DOI 10.17707/Agricult Forest.63.1.10.

Smykov A.V., Fedorova O.S., Suchkova J.E. Drought resistance and susceptibility of fungal diseases in hybrid forms of peach (Prunus persica (L.). Variety study and protection of plant variety rights. 2013;4:30-35.

Sokolova E.A., Shoferistov E.P. Anatomical structure of peach and nectarine species and cultivars. Scientific and Technical. bull All Union. Order of Lenin and the Order of Friendship of Peoples of the Research Institute of Plant Production them. N.I. Vavilov (Leningrad). 1991;212:33-37.

Acknowledgements. This work was supported by the Russian Science Foundation, project no. 19-16-00091.

Conflict of interest.The authors declare no conflict of interest. 